\title{
A responsabilidade compartilhada no Direito da Criança e Adolescente como dimensão da solidariedade: intersecção entre público e privado
}

\section{The shared responsibility in the Child and Adolescent Law as a dimension of solidarity: intersection between public and private}

\author{
Ismael Francisco de Souza*
}

Resumo: O artigo analisará a responsabilização estendida aos particulares por meio da solidariedade, esta que é caracterizadora da vinculação dos mesmos aos direitos fundamentais de crianças e adolescentes e que se reveste de um verdadeiro dever de ação e de não omissão nos casos de violação. Assim, inicialmente abordar-se-á a constitucionalização do direito privado no paradigma do Estado Democrático de Direito contemporâneo; a solidariedade em seus aspectos conceituais e como princípio basilar do ordenamento constitucional brasileiro; e por fim, a caracterização da responsabilidade compartilhada com a família e sociedade em geral, instâncias de excelência das relações privadas, pela garantia dos direitos de crianças e adolescentes como uma das dimensões da solidariedade. Contudo, entende-se que a sociedade se torna lócus ideal de liberdade do indivíduo, de colaboração mútua e, ainda, espaço harmonioso no qual dialogicamente serão efetivados direitos e deveres numa lógica de solidariedade. O método científico adotado na pesquisa foi o dedutivo com pesquisa bibliográfica.

Palavras-chave: Direito da Criança. Solidariedade. Público e privado.

Abstract: The article will analyze the responsibility extended to individuals through solidarity, characterizing their linkage to the fundamental rights of children and adolescents and that it has a real duty to act and not to omit in cases of violation. Thus, initially the constitutionalisation of private law in the

\footnotetext{
* Doutor em Direito pela Universidade de Santa Cruz do Sul - RS (UNISC). Professor e pesquisador Permanente do Programa de Pós-Graduação - Mestrado em Direito e da graduação em Direito na disciplina de Direito da Criança e do Adolescente (UNESC). Líder do Grupo de Pesquisa: Direito da Criança e do Adolescente e Políticas Públicas. Pesquisador do Núcleo de pesquisa em Política, Estado e Direito (NUPED). Colaborador externo do Grupo de Pesquisa Políticas Públicas de Inclusão Social e do Grupo de Estudos em Direitos Humanos de Crianças, Adolescentes e Jovens do PPGD/UNISC.
} 
paradigm of the contemporary Democratic State of Law will be approached; solidarity in its conceptual aspects and as a basic principle of the Brazilian constitutional order; the characterization of shared responsibility with the family and society in general, instances of excellence in private relations, for guaranteeing the rights of children and adolescents as one of the dimensions solidarity. Finally, it is understood that society becomes the ideal locus of freedom of the individual, of mutual collaboration and, also, harmonious space through which dialogue and rights will be effected in a logic of solidarity. The scientific method adopted in search was the deductive one with bibliographical research.

Keywords: Children's Rights. Solidarity. Public and private.

\section{Introdução}

Partindo de uma perspectiva visando às mudanças ocorridas em função da constitucionalização do direito, paradigma pelo qual é possível afirmar a recepção pelo ordenamento constitucional publicista de conteúdos antes tidos por excelência como temas de direito privado, todo o ordenamento jurídico acaba, pela força normativa Constitucional, por reproduzir axiologicamente e materialmente seu conteúdo. Neste sentido, os princípios constitucionais e aqueles típicos do direito privado passam a serem vetores interpretativos dos valores constitucionais, destacando-se entre esses, a solidariedade.

A ideia de solidariedade a que este artigo se refere apresenta-se enquanto dimensão materializadora dos direitos fundamentais de crianças e adolescentes garantidos por meio da responsabilidade compartilhada entre família, sociedade e Estado, enquanto agentes responsáveis solidariamente a partir de ordenamento constitucional pela proteção daqueles com até 18 anos de idade.

A tríplice responsabilidade compartilhada entre família, sociedade e Estado remete a ideia basilar de que os direitos da população infanto-juvenil serão garantidos por meio da atuação oriunda dessas três instancias, ou seja, por meio da responsabilidade pública do Estado no cumprimento dos dispositivos constitucionais e legais, que assegurará, além do respeito ao desenvolvimento de crianças e adolescentes em condição peculiar, as condições 
sociais, ambientais e familiares adequadas ao desenvolvimento de potencialidades individuais e da sociabilidade. Complementa-se ainda esta responsabilidade, na perspectiva da responsabilização, o reconhecimento e garantia de direitos por parte da família e da sociedade. O presente trabalho trata especificamente destas duas últimas instâncias responsáveis, ou seja, família e sociedade, tendo em vista que se constituem de relações privadas com novos deveres impostos pelos valores constitucionais reordenados, tanto da natureza dessas relações, quanto do direito da população infanto-juvenil.

Como já pressuposto, este artigo não será delimitado no dever imperativo legalmente estabelecido à atuação do Estado na garantia dos direitos de crianças e adolescentes, onde a partir das políticas públicas possui um mecanismo de excelência para a implementação desses direitos fundamentais. A análise se pautará na responsabilização estendida aos particulares por meio da solidariedade que é caracterizadora da vinculação dos mesmos aos direitos fundamentais de crianças e adolescentes. Entende-se que esta esteja revestida de um verdadeiro dever de agir e de não omissão nos casos de violação.

Portanto, inicialmente se abordará a constitucionalização do direito privado no paradigma do Estado Democrático de Direito contemporâneo; a solidariedade em seus aspectos conceituais e como princípio basilar do ordenamento constitucional brasileiro; por fim a caracterização da responsabilidade compartilhada com a família e sociedade em geral, instâncias de excelência das relações privadas, pela garantia dos direitos de crianças e adolescentes como uma das dimensões da solidariedade.

\section{A Constitucionalização como novo paradigma para as relações privadas.}

A compreensão da constitucionalização do direito como matriz axiológica e interpretativa para os ordenamentos jurídicos em suas diversas dimensões, especialmente no âmbito das relações privadas, requer a abordagem dos direitos fundamentais enquanto seus principais instrumentos de materialização. Estes direitos foram inseridos em momentos e contextos sociais diferenciados, iniciando-se por meio da inserção dos direitos e liberdades individuais. A 
localização histórica e temporal remete à Revolução Francesa, em específico a Declaração dos Direitos do Homem e do Cidadão de 1789. Com a emergência da Revolução Francesa surge o modelo Estado Liberal responsável pelo rompimento com o modelo Absolutista. Pautado no modo de produção capitalista, esta nova forma de Estado, influenciado pelas ideias iluministas, foi responsável por um considerável avanço ao centralizar no homem, não mais em uma ordem divina, as discussões de matriz política e jurídica.

O Estado liberal vincula-se diretamente a defesa e garantia das liberdades individuais por meio da lei, ou seja, o Estado neste contexto zela pelo exercício da liberdade dos cidadãos de forma que os mesmos possam de forma harmoniosa perseguir seus objetivos. Nesse sentido, o Estado coloca-se à disposição do indivíduo a serviço do interesse comum a todos aqueles que a partir de então se encontraram livres e iguais (LEAL, 2007). O contexto de liberdade e não interferência do Estado nas relações particulares torna-se terreno ideal para codificação das leis civis, tendo em vista que as relações jurídicas dos cidadãos se centram no individualismo, patrimonialismo e autonomia de vontade. Dentre os papeis agora desempenhados, ao Estado caberia garantir o exercício do direito à propriedade privada e não invadir as relações de caráter privado, ou seja, a liberdade de contratar foi um dos pilares dessas codificações (CARDOSO, 2010).

Esse modelo constituiu-se no que se chamou de Estado garantidor, centrado no Poder Legislativo como âmbito de referência dos direitos fundamentais de primeira dimensão. Os direitos fundamentais de primeira dimensão (direito à vida, à liberdade, à propriedade, à expressão e entre outros), caracterizam-se pelo viés do individualismo que, diante do Estado, acabam por impor-lhe o dever de abster-se como garantia do exercício da liberdade individual. Por essa razão Sarlet (2012) os denomina como direitos fundamentais negativos.

É contemporânea ao surgimento do Estado Liberal a ideia de diferenciação entre direito público e privado, sendo aquele para desempenhar o papel de disciplinar o Estado e sua organização e este com a responsabilidade de regulamentar os interesses da sociedade civil e da organização econômica (FACCHINI NETO, 2010). Assim, ao Estado coube regular suas relações para 
com os subordinados - desiguais, enquanto o direito privado regularia as relações entre iguais (relações particulares).

Esta separação do direito remete à ideia central da codificação liberal, a qual acarretou a incidência das Constituições como referente das relações entre Estado e indivíduos e a incidência dos Códigos Civis como regulamentadores das relações entre mercado e sociedade (SARMENTO, 2006).

A partir do século XIX, por meio de reivindicações de cunho social pela classe trabalhadora organizada, inicia-se no ideário constitucional a inserção de direitos cuja população integralmente passa a ser titular. Inicia-se neste contexto o chamado constitucionalismo social, tendo como dois marcos fundamentais a Constituição mexicana de 1917 e a Constituição de Weimar de 1919, na Alemanha. Este constitucionalismo, aliado ao insurgente Estado Social, torna-se a matriz para a intervenção formal tanto nas relações privadas quanto na economia (CARVALHO, 2012, p.47-49).

Assim, tanto o século XIX quanto o século XX tornam-se o berço do novo modelo denominado Estado Social, tendo em vista a ineficácia do Estado Liberal no tocante à organização da sociedade que naquele contexto sofria as consequências nefastas do modo de produção capitalista, destacando-se entre tais consequências as desigualdades sociais. Neste contexto o Estado passa a intervir com objetivo de promover e garantir a igualdade efetiva entre todos, atendendo às necessidades coletivas por meio de direitos. Há a transmutação de Estado garantidor para prestador, ou seja, surgem os direitos considerados de segunda dimensão, que seriam positivados, posteriormente, nas constituições consideradas modernas (BAGATINI, 2014).

Outro momento paradigmático para os países no marco do constitucionalismo ocorre no período que se seguiu após a Primeira Guerra Mundial com a divisão pautada na dicotomia Estado e sociedade civil, em contexto de conflitos nas diversas camadas populacionais e sociais que objetivavam interesses diversos, bem como a intervenção estatal minimamente direcionada à economia para a garantia da livre concorrência, mas que, paradoxalmente, torna-se motor de desigualdades socioeconômicas. Por essa razão, muda-se a forma de reconhecer o direito, agora entendido como conjunto de regras, mandamentos de otimização, ou seja, princípios, além de apontar os 
Revista Brasileira de História \& Ciências Sociais - RBHCS

Vol. 12 No 24, Julho - Dezembro de 2020

objetivos que se esperam que sejam realizados pelo Estado constitucional (OLIVEIRA, 2002).

Leal (2007) aborda este período afirmando que o Estado, após a Segunda Guerra, atua sobre a economia regulando-a de forma a promover a reconstrução e crescimento daqueles que foram destruídos pelos conflitos. Alia-se ainda a este argumento o fato de que a legislação de cunho liberal, pautada na igualdade formal perante a lei, não impediu a desigualdade, mas potencializou a exploração daqueles considerados mais fracos e vulneráveis pelos mais fortes (REIS, 2003).

Salientam-se agora nas Constituições os direitos fundamentais de segunda dimensão, pautados na igualdade material e rompendo com o sentido meramente formal, materializado nos direitos fundamentais de primeira dimensão. Por meio destes, promovem-se direitos como saúde, educação, moradia, previdência social, trabalho, assistência, portanto, protege os cidadãos contra riscos individuais e sociais (LEAL, 2007).

No entanto, o que se observou foi igual esgotamento do modelo de Estado Social, o que abriu a possibilidade para o estabelecimento do Estado Democrático de Direito ou Estado Pós-Social, cujo objetivo é a garantia da igualdade com vista à dignidade humana, transformando, assim, a realidade social (Sarmento 2006).

Neste sentindo, no que tange as mudanças no tocante às dimensões de direitos fundamentais, o que se observou nos séculos XVIII e XX em relação às leis oriundas de ambos os modelos de Estado (liberal e social) é a separação total entre as funções das Constituições e as codificações civilistas, o que acarretou na distinção e fortalecimento da ideia de direito público e privado. Somente a partir das mudanças após a Segunda Guerra Mundial que se observou um reordenamento jurídico nos países ocidentais, responsáveis por reorganizar hierarquicamente suas leis de forma a colocar a Constituição no ápice (ou centro) dos sistemas jurídicos. Por meio desta alteração foi possível a chamada constitucionalização do direito privado.

A constitucionalização do direito privado não significou exclusivamente a acolhida por parte da Constituição de matérias ou conteúdos que anteriormente eram tratadas especificamente pelo direito privado, mas sim, de um fenômeno 
pelo qual o direito privado, seja vinculado ao âmbito civilista ou das leis especiais, passa a ser interpretado e aplicado de acordo com o conteúdo axiológico da Constituição (PERLINGIERI, 2008).

De acordo com Reis (2003), em função do princípio da constitucionalidade, é estabelecida a exigência de acordar aos princípios da Constituição todos os atos praticados, sob pena de inexistência - nulidade, anulabilidade ou ineficácia - ou seja, não há como se conceber a ideia de um direito privado autônomo, mas todo o ordenamento torna-se constitucionalizado. Assim, alterando o paradigma de forma a proteger a pessoa humana e não mais a proteção patrimonial ditada pelo ideal burguês, central no sistema liberal. Por esta ideia, o autor afirma ocorrer o fenômeno da despatrimonialização do direito privado em virtude da sua obediência à constitucionalização, que requer a predominância do princípio da dignidade da pessoa humana, ocorrendo, dessa forma, “[...] a repersonalização do direito privado, no sentido de (re)colocar o indivíduo no topo da proteção deste direito privado" (REIS, 2003, p.780).

Apesar desse movimento centralizador das Constituições iniciar após a Segunda Guerra Mundial, no Brasil verifica-se que a norma responsável pela unificação do ordenamento privado surge apenas em 1988 por meio da Constituição Federal promulgada em 05 de outubro. Nesta, as normas de direito privado atingem à propriedade, à família, aos contratos, ou seja, àquele conteúdo da seara da autonomia do indivíduo que passam a ter na Constituição e não mais no Código Civil, sua fonte primária. Destaca-se na Constituição Federal de 1988 sua centralidade axiológica na dignidade da pessoa humana, na erradicação da pobreza, na liberdade, na igualdade material e na solidariedade social, caracterizando um verdadeiro reordenamento no âmbito da interpretação e aplicação das leis civis.

Tendo em vista o objetivo desse trabalho de demonstrar o princípio da responsabilidade compartilhada do Direito da Criança e do Adolescente como dimensão da solidariedade, importa apresentar a solidariedade como elemento intrínseco à aplicação dos valores e direitos fundamentais nas relações privadas. Nesse sentido, parte-se do pressuposto de que a solidariedade é elemento integrador do ordenamento jurídico. 


\section{Solidariedade: aspectos conceituais}

Antes de abordar aspectos fundacionais a respeito da solidariedade, importa salientar sua vinculação aos direitos fundamentais. Nesse sentido, tendo como ponto de partida a igualdade como elemento pilar dos direitos chamados de segunda dimensão, a solidariedade foi responsável por introduzir na ordem jurídica o respeito à dignidade humana, caracterizando aqueles direitos fundamentais que seriam reconhecidos como de terceira dimensão insere-se a própria solidariedade nesta classificação.

No tocante a abordagem deste artigo, a solidariedade será abordada pelo viés da Constituição Federal de 1988, tendo em vista o fato de ser esta a carta constitucional responsável, não apenas pela constitucionalização do direito privado, mas pelo reordenamento de direitos de crianças e adolescentes, incluindo o âmbito da responsabilização pela garantia desses direitos não apenas ao Estado, mas a sociedade civil e a família, na pessoa de cada um de seus membros. Ou seja, há agora uma responsabilização individual, privada, que será caracterizada com mais propriedade no próximo tópico.

A Constituição Federal de 1988, como já mencionado, inovou ao introduzir no ordenamento jurídico um conjunto de princípios que passaram a constituir a diretriz do direito privado, como a dignidade humana e solidariedade social, caracterizando-os como princípios fundamentais do Estado brasileiro (SANTOS, 2009). Esta introdução de princípios reorganizadores do sistema jurídico acabou por tornar emblemática a nova hermenêutica a ser aplicada nas normas de direito privado, passando-as a serem lidas, interpretadas a aplicadas por meio da Constituição (FACHIN, 2009).

O advento da democracia após um longo período de regime totalitário acarretou a necessidade de alteração política por meio da assembleia constituinte de 1987, situação que, nas palavras de Fachin (2009, p. 21), tornou “a Carta Magna da jovem nação brasileira algo mais que a Constituição de papel que Ferdinand Lassale desenhara nos idos do século XIX”. Ou seja, a Constituição Federal de 1988 estaria, naquele contexto, de acordo com os fatores reais de poder estabelecidos, ressignificando as instituições políticas a 
partir dos anseios dos movimentos sociais partícipes daquele momento. Era a constituição real (FACHIN, 2009).

Neste contexto se eleva a dignidade humana como princípio fundamental da República assim como a solidariedade enquanto princípio e direito, impactando ambos os princípios no ordenamento jurídico de forma a reordenar o sistema e cultura jurídica até então em vigor. Assim, a solidariedade enquanto um princípio, um mandato de otimização, deverá ser concretizada no plano fático o máximo possível sempre, constituindo-se ainda como cláusula pétrea. Enquanto direito fundamental, a solidariedade poderá ser exigida perante o Estado e sociedade, destacando-se nesta dimensão o vínculo entre os indivíduos, tendo em vista que a existência da solidariedade depende da relação de um individuo para com o outro - relação do indivíduo com o coletivo. Neste sentido,

[...] estou solidariamente unido ao outro, como companheiro, como "um dos nossos"; como indivíduo insubstituível eu devo ao outro o mesmo respeito, como "uma entre todas" as pessoas, que merecem um tratamento justo enquanto indivíduos inconfundíveis. A "solidariedade" baseada na qualidade de membro lembra o liame social que une a todos: um por todos. $\mathrm{O}$ igualitarismo implacável da "justiça” exige, pelo contrário, sensibilidade para com as diferenças que distinguem um indivíduo do outro. Cada um exige do outro o respeito por sua alteridade (HABERMAS, 2004, p. 21).

Ainda na seara conceitual, a abordagem da solidariedade remete em um primeiro momento à sua vinculação às funções do Estado, não excluindo desta instância a própria formação da sociedade como âmbito responsável pela complementação e aperfeiçoamento de outros valores significativos como a igualdade e a liberdade (SILVA, 2008).

A abordagem da solidariedade compõe, dessa forma, duas dimensões, seja enquanto princípio fundamental e/ou enquanto direito fundamental, objetivando em ambos, subsidiar a ação do indivíduo na sociedade de forma que suas condutas sejam pautadas pela ética, tornando-os assim responsáveis para com a organização social e os demais indivíduos que a compõem.

Importa destacar na dimensão principiológica que a solidariedade constitui um dos mecanismos de materialização da dignidade humana. Nesse 
sentido, ambos os princípios se relacionam e impactam, em igual medida, tanto os ordenamentos jurídicos contemporâneos, marcadamente constitucionais, quanto à dinâmica das relações nas sociedades modernas, tendo em vista que a solidariedade é imposta como direito e como dever.

A abordagem de Duguit (2009) contribuiu significativamente para o fortalecimento da ideia da solidariedade enquanto regra de conduta basilar para as relações sociais, considerando que para este autor, é a sociedade - o conjunto das relações que nela se estabelecem - a dinâmica sobre a qual se fundamenta o direito. O autor pactua ainda da teoria clássica de Durkheim (2010) analisando o direito a partir do fato social e, consequentemente, verificando-se a solidariedade nesta base teórica, no tocante a abordagem ao sentimento de justiça e também referente à divisão do trabalho. Neste sentido, Duguit compartilha da ideia de que as relações inseridas na sociedade, pautadas na solidariedade adjetivada como "por semelhança" e também naquela necessária à "divisão do trabalho", tem em vista que os indivíduos na sociedade possuem necessidades comuns e diferentes, que acarretam na formação desses vínculos, aptos a ajudar-lhes reciprocamente e assegurar a satisfação dessas necessidades (DUGUIT, 2009).

É preciso considerar que a contemporaneidade traz em sua essência a pluralidade, situação fática que requer maior participação e comprometimento individual, tanto na gestão do público quanto para com o próprio desenvolvimento pessoal. Esta participação teria na solidariedade um de seus principais motrizes.

Este fundamento remete a concepção do direito em sua dimensão objetiva, tendo a solidariedade social como diretriz. Nesse sentido, é possível afirmar a existência da solidariedade em todas as organizações sociais, tanto naquelas em que existam necessidades comuns, quanto naquelas em que essa similitude não exista. Sobre esse fundamento o autor categoricamente firma a solidariedade social como objetivo maior, tanto do direito (valor jurídico) quanto da conduta individual (valor social) (DUGUIT, 2009).

Na lógica funcional de Duguit, um ato só tem valor social e jurídico se for determinado por um fim conforme a "solidariedade social", e não porque ele tem como sustentação unicamente a vontade do sujeito. [...] Na medida em que para a 
formação da ordem social é preciso existir manifestações de vontade dos indivíduos, que a ordem social implica um processo de exteriorização das vontades individuais, os atos de vontade não terão valores jurídicos pela simples manifestação da vontade do sujeito. Será precisa que os atos individuais, necessários à criação da ordem social, sejam determinados pelo fim da "solidariedade social". (FARIAS, 1998, p. 227).

A opção por Duguit neste trabalho se justifica pela ideia de que o fundamento social é basilar da liberdade individual, pautando as condutas dos indivíduos em sociedade por meio de normas sociais e jurídicas que assim determinam, exigindo de cada pessoa um comportamento solidário, consolidando um verdadeiro dever ético para com os demais. Por essa perspectiva o autor aponta a funcionalidade do direito como diretriz ao lembrar indivíduos e sociedade de suas responsabilidades para com o equilíbrio das relações sociais, por meio dos deveres éticos de solidariedade.

Principalmente no que tange a um comprometimento com a defesa dos direitos de crianças e adolescentes, o mesmo deve ser considerado de maneira compartilhada. Não é responsabilidade apenas do Poder Público, através de políticas públicas, o dever da implementação, bem como garantia dos direitos da população infanto-juvenil, mas da sociedade em geral, cada um dos seus membros deve compartilhá-la, no sentido de atuar sempre, jamais se omitindo individualmente diante da violação desses direitos.

\section{A responsabilidade compartilhada como dimensão da solidariedade no Direito da Criança e do Adolescente}

A solidariedade fixada na ordem constitucional brasileira a partir de 1988 resulta de duas situações significativas, a saber, a ditadura militar, que persistiu por longo período da história nacional e foi responsável pela supressão de direitos e garantias fundamentais individuais, e o reordenamento de ordem global ocorrido após a Segunda Guerra Mundial, responsável pela elevação da dignidade humana como apoio da evolução dos direitos fundamentais. Assim, a solidariedade passa a ocupar importante papel neste novo paradigma jurídico, sendo responsável não apenas pela manutenção da ordem e paz social, mas igualmente garantidora da liberdade e dignidade, reordenando valorativamente a conduta de cada individuo no sentido da responsabilidade social. 
Por essa razão, há que se afirmar que tanto a constitucionalização do direito privado quanto a solidariedade como novo paradigma acarretaram a vinculação dos particulares de maneira direta aos direitos fundamentais. Nesse sentido, deve-se considerar, a título de incidência desses direitos no âmbito da vida privada, a determinação constitucional do artigo $5^{\circ}, \S 1^{\circ}$ referente à aplicabilidade imediata e direta desses direitos e princípios, o que não exclui a seara das relações e do direito privado (SARLET, 2000).

Ao se constatar a eficácia dos direitos fundamentais, a mesma deve ser analisada tanto verticalmente como horizontalmente nas relações regulamentadas pelo direito privado, em que pese às divergências relativas à sua aplicação nessa instância. Primeiramente, a eficácia horizontal refere-se à vinculação dos particulares nas suas relações entre iguais. Sob esta perspectiva, a organização estatal e sua estrutura estarão solidificadas no sentido de garantir os direitos fundamentais por meio da aplicação das normas de direito privado nos casos levados às instâncias estatais pelos particulares, solucionando possíveis conflitos (SARLET, 2000). Já no tocante à eficácia vertical, refere-se à garantia dos indivíduos perante a atuação estatal. O Estado, nesse sentido, tem a obrigação de não agredir tais direitos como também fazer com que os particulares os respeitem.

A aplicação e vinculação dos particulares aos direitos fundamentais torna-se discussão central para a problemática deste trabalho na medida em que se questiona a possibilidade de responsabilizar o cidadão pela violação e não garantia de direitos fundamentais de crianças e adolescentes. É preciso salientar que a abordagem da proteção dos direitos e garantias de indivíduos perante o poder estatal, por meio da perspectiva da eficácia vertical, não se mostrou suficiente ao longo da história, tendo em vista que os particulares igualmente violam direitos fundamentais. A questão é que a proteção nas relações interprivadas exige a solidariedade como condão de responsabilidade social, ao compartilhar com os indivíduos o dever de ação nos casos de violação de direitos fundamentais, o que obrigatoriamente os vincula horizontalmente.

Inserido nessa lógica, o comunitarismo também se assenta na solidariedade, por esta perspectiva é possível afirmar a noção do respeito aos direitos fundamentais, logo, a vinculação entre os particulares, já que os 
Revista Brasileira de História \& Ciências Sociais - RBHCS

Vol. 12 No 24, Julho - Dezembro de 2020

indivíduos solidários não estariam sujeitos a tratar os demais como instrumentos, mas como fins em si mesmos, corresponsabilizando-se pelos direitos fundamentais inalienáveis dos demais membros da comunidade (ETZIONI, 2001).

Por essas razões que a solidariedade inserida no ordenamento constitucional brasileiro representa verdadeiro elemento vinculador de todos para com os vulneráveis, no caso em tela, as crianças e os adolescentes. No âmbito do direito, a criança torna-se sujeito de cuidados especiais por sua condição peculiar de pessoa em desenvolvimento através do reconhecimento dos seus direitos humanos. Destaca-se, na articulação dos direitos destinados à infância, a ONU - Convenção das Nações Unidas sobre os Direitos da Criança, responsável pela inserção definitiva da Teoria da Proteção Integral.

A ideia central da proteção integral à criança e ao adolescente foi capaz de articular uma teoria própria em determinado momento histórico, porque conseguiu ao mesmo tempo conjugar necessidades sociais prementes aos elementos complexos que envolveram mudança de valores, princípios, regras e neste contexto conviver com a perspectiva emancipadora do reconhecimento dos direitos fundamentais à criança e ao adolescente. (CUSTÓDIO, 2008, p.22).

A Convenção da ONU sobre os Direitos da Criança resultou dos trabalhos de comemoração dos vinte anos da Declaração dos Direitos das Crianças e Ano Internacional da Criança de 1959 que, por iniciativa da delegação polonesa, formulou o projeto da convenção com ampla participação de representantes dos quarenta e três países membros da Comissão de Direitos Humanos da ONU e de vários organismos intergovernamentais e organizações não governamentais. Nesse sentido, "a Convenção supera, por decisão dos próprios Estados, visões excludentes sobre diferenças culturais que impedem de construir padrões jurídicos comuns para todas as pessoas, em relação a seus direitos fundamentais." (VERONESE, 2015).

Destaca-se para o fato do preâmbulo da Convenção fundamentar a solidariedade como um dos pilares essenciais para a vida em sociedade, apontando ainda, para a necessidade de que as crianças, para que estejam preparadas para viver em sociedade, sejam educadas "[...] de acordo com os ideais proclamados na Carta das Nações Unidas, especialmente com espírito de 
paz, dignidade, tolerância, liberdade, igualdade e solidariedade." (ONU, 1989).

Ressalta-se ainda neste importante documento o artigo $5^{\circ}$, que aduz:

Os Estados Partes respeitarão as responsabilidades, os direitos e os deveres dos pais ou, onde for o caso, dos membros da família ampliada ou da comunidade, conforme determinem os costumes locais, dos tutores ou de outras pessoas legalmente responsáveis, de proporcionar à criança instrução e orientação adequadas e acordes com a evolução de sua capacidade no exercício dos direitos reconhecidos na presente Convenção. (ONU, 1989).

Neste sentido, há a garantia da autonomia dos pais e responsáveis na escolha da forma como conduzirão a criação, instrução e orientação de seus filhos. Salienta-se, no entanto, que a autoridade exercida pelos pais, ou por entidades administrativas nesta condição, é limitada pelo ordenamento jurídico e pelos direitos fundamentais de crianças e adolescentes, devendo a família respeitar esses direitos e não extrapolar os limites legais reconhecidos, para que as crianças alcancem o pleno desenvolvimento em harmonia com os princípios da Convenção e gradativamente de acordo com o desenvolvimento de suas faculdades possam exercer seus direitos com autonomia. Neste sentido:

\begin{abstract}
A Convenção, então, opera como um ordenador das relações entre a criança, o Estado e a família, que se estrutura a partir do reconhecimento de direitos e deveres recíprocos. Seguindo a tradição contida na Declaração Universal dos Direitos Humanos, a Convenção é profundamente respeitosa com a relação criança-família, enfatizando o papel das políticas sociais básicas e de proteção da criança e da família, limitando a intervenção tutelar do Estado a uma última instância que supõe que falharam os esforços da família e dos programas sociais gerais. (PEREIRA, 1996, p.67).
\end{abstract}

Por esta razão, a Convenção define os direitos da criança mais emblematicamente em relação à sociedade do que em relação à família, determinando a esta instância o direito de ser protegida contra intervenções arbitrárias e ilegais do Estado, situação que afetaria a própria criança. Salientase, no entanto, que seria legítima a intervenção do Estado para a proteção da criança. Assim determina o artigo 18 da Convenção: 
1. Os Estados Partes enviarão os seus melhores esforços a fim de assegurar o reconhecimento do princípio de que ambos os pais têm obrigações comuns com relação à educação e ao desenvolvimento da criança. Caberá aos pais ou, quando for o caso, aos representantes legais, a responsabilidade primordial pela educação e pelo desenvolvimento da criança. Sua preocupação fundamental visará ao interesse maior da criança [...]. (ONU, 1989).

Neste sentido, identifica-se a responsabilidade solidária dos pais junto do Poder Público, ficando o primeiro primordialmente com a função de educar seus filhos e ao segundo, de apoiá-los nessa função.

A solidariedade inicialmente apontada pela Convenção encontra materialidade no ordenamento jurídico brasileiro a partir da Constituição da República Federativa do Brasil de 1988, carta que alterou definitivamente o paradigma que imperava até então sobre a infância.

A ruptura definitiva ocorre somente com o advento da Doutrina da Proteção Integral, pois é ela que define que crianças e adolescentes devem ser considerados sujeitos de direito que se encontram em um momento peculiar de desenvolvimento e que, em decorrência de tal condição, merecem prioridade no atendimento de seus interesses. (VIEIRA, VERONESE, 2006, p. 37).

Fruto da mobilização da sociedade civil e de entidades não governamentais, o que já caracteriza a solidariedade entre particulares no tocante à proteção da infância, a inclusão dos direitos da criança e do adolescente foi exaustivamente discutida durante a Assembleia Nacional Constituinte, resultando na redação do seguinte artigo da Constituição de 1988:

Art. 227. É dever da família, da sociedade e do Estado assegurar à criança e ao adolescente, com absoluta prioridade, o direito à vida, à saúde, à alimentação, à educação, ao lazer, à profissionalização, à cultura, à dignidade, ao respeito, à liberdade e à convivência familiar e comunitária, além de colocá-los a salvo de toda forma de negligência, discriminação, exploração, violência, crueldade e opressão. (BRASIL, 1988).

Verifica-se no referido artigo uma consagração máxima em âmbito constitucional da Teoria da Proteção Integral, destacando-se na norma os princípios basilares como a prioridade absoluta e a tríplice responsabilidade 
compartilhada entre a família, a sociedade e o Estado para a efetivação dos direitos. Destacam-se ainda os direitos especiais de proteção, bem como as diretrizes para uma política de atendimento dos direitos da criança e do adolescente.

É primordial que se compreenda o avanço acarretado pela inserção constitucional do artigo 227, responsável por incorporar a Teoria da Proteção Integral que reconhece direitos fundamentais às crianças e adolescentes, "atribuindo-lhes o status de prioridade absoluta e conferindo a responsabilidade à família, ao Estado e à sociedade de assegurar sua efetivação.” (CUSTÓDIO, 2006, p. 16).

A Constituição de 1988 reveste-se de verdadeiro marco na história jurídica do país ao instituir os direitos humanos e elevar a dignidade humana ao patamar de fundamento constitucional. Nesse sentido, tanto a dignidade humana quanto os direitos fundamentais acabam por constituir os princípios constitucionais incorporadores de exigências de justiça e dos valores éticos, dando suporte axiológico ao sistema jurídico brasileiro (PIOVESAN, 2009).

Nesta perspectiva, se encontra a solidariedade também como pressuposto para a determinação de cumprimento dos direitos fundamentais de crianças e adolescentes no âmbito das relações privadas, elevando a família e a sociedade como responsáveis. Esta observação é importante diante do atual cenário que não apresenta mais contornos definidos entre as instâncias públicas e privadas no tocante aos direitos humanos e fundamentais de crianças e adolescente, pois "[...] princípio emancipatórios atrelados aos direitos humanos e democracia, não podem mais permanecer cingidos com exclusividade à esfera das relações em que o Estado se faça presente." (SARMENTO, 2010, p. 49).

O "princípio da tríplice-responsabilidade", que deve ser compartilhada entre família, sociedade e Estado, reveste-se da dimensão da solidariedade, não do ponto de vista da obrigatoriedade, provedoras dos direitos da população infanto-juvenil por parte do Estado, mas porque cabem a todos, família e sociedade civil em geral, na prática das relações cotidianas, resguardar os direitos da população infanto-juvenil. Esses direitos devem ser garantidos pelos três âmbitos: família, sociedade e Estado. 
Em suma, a garantia dos direitos da criança e do adolescente perpassa a responsabilidade pública no sentido de cumprir e pôr em prática aquilo que está disposto no texto legal, bem como perpassa o respeito à condição peculiar de desenvolvimento, assegurando condições familiares e ambientais adequadas ao estímulo das potencialidades individuais e de sua sociabilidade. Seguindo os passos dessa análise, a cidadania de crianças e adolescentes refere-se ao reconhecimento dos direitos da população infanto-juvenil, no plano formal e legal, por parte do Estado, da família e da sociedade. (RAPOSO, 2009, p. 47-48).

A materialização da solidariedade por meio da responsabilidade compartilhada entre família e sociedade é facilmente vislumbrada quando analisada por meio dos direitos protetivos encontrados na parte final do artigo 227 assim como no parágrafo $4^{\circ}$ (BRASIL, 1988) ao afirmar que "a lei punirá severamente o abuso, a violência e a exploração sexual da criança e do adolescente.". Tais direitos protetivos afirmam a regra constitucional de efetividade e garantia de direitos fundamentais exigida não apenas do Estado, mas igualmente da família e da sociedade, no tocante a afastar a criança e o adolescente de toda forma de negligência, discriminação, exploração, violência, crueldade ou opressão sob pena de responsabilização individual. Nesta diretriz, o artigo $5^{\circ}$ da Lei n. 8069/90 do Estatuto da Criança e do Adolescente aduz que "nenhuma criança ou adolescente será objeto de qualquer forma de negligência, discriminação, exploração, violência, crueldade e opressão, punido na forma da lei qualquer atentado, por ação ou omissão, aos seus direitos fundamentais." (BRASIL, 1990).

Ainda na seara do Estatuto, o cumprimento da determinação constitucional encontra-se garantido a partir do artigo 70, referencial específico das medidas de prevenção, determinando que "é dever de todos prevenir a ocorrência de ameaça ou violação dos direitos da criança e do adolescente." (BRASIL, 1990). Este dever, representativo da solidariedade, coaduna com o disposto no artigo 73 do mesmo diploma, ao afirmar que "a inobservância das normas de prevenção importará em responsabilidade da pessoa física ou jurídica, nos termos desta Lei.” (BRASIL, 1990).

Importa salientar que a elevação da dignidade humana, a fundamento constitucional, relaciona-se diretamente à necessidade de se pautar o tratamento dispensado às crianças e adolescentes pela "humanidade", seja nas 
relações verticais do Estado, seja nas relações horizontais entre indivíduos na esfera privada. É a vedação oriunda do ordenamento jurídico pautado na solidariedade que não admite qualquer tratamento desumano ou degradante. $\mathrm{O}$ princípio da dignidade humana quando não garantido nas relações privadas que as crianças e adolescentes estão submetidos é violado sempre que estes sofrerem qualquer tipo de maus-tratos. A dignidade humana não coabita com o desrespeito, a humilhação e o descaso com a integridade física e psíquica do ser humano.

A vinculação dos particulares na garantia dos direitos de crianças e adolescentes nas relações privadas e/ou sociais é reflexo na nova condição de sujeitos de direitos que obrigatoriamente exige respeito à sua titularidade de direitos fundamentais, não mais admitindo que a população infanto-juvenil seja mero objeto passivo da discricionariedade dos adultos.

A condição de sujeitos de direitos remete à compreensão da relação entre igualdade e cidadania, relação esta primordial à ideia de solidariedade, tendo em vista que os vínculos de solidariedade são percebidos por meio de articulação mista necessária à coesão social esperada nas sociedades contemporâneas, marcadamente plurais e complexas (DOMINGUES, 2002, p. 173). Nessa lógica, é urgente uma reformulação ética e política capaz de restaurar o sujeito responsável, consolidando a solidariedade nas relações privadas de forma a garantir direitos de crianças e adolescentes na pluralidade da sociedade contemporânea. Sobre essa abordagem, afirma Morin (2000 p. 7172):

O problema da responsabilidade deve ser colocado em termos complexos. De um lado, cada um deve reconhecer-se responsável por suas palavras, por seus escritos, por seus atos. De outro, tomando como base a ecologia da ação, ninguém é responsável pelo modo como suas palavras são entendidas, como seus escritos são compreendidos, como seus atos são mal interpretados, distorcidos. [...] Há outra responsabilidade, que é oriunda de nossa comunidade de destino planetário. E ela que sempre relembra nossa parcela de responsabilidade nesse destino comum, e não somente no que diz respeito ao presente, mas também ao futuro. (MORIN, 2000 p. 71-72).

A solidariedade se constitui em processos sociais específicos e através deles, indivíduos e sociedade - entendida como coletividade, reconhecem 
Revista Brasileira de História \& Ciências Sociais - RBHCS

Vol. $12 N^{\circ}$ 24, Julho - Dezembro de 2020

socialmente direitos e deveres considerados justos perante todos os envolvidos. Sendo assim, a solidariedade é promovida por vias diferenciadas, que por vezes se reforçam ou tornam-se conflituosas, tanto no consciente coletivo, quanto no individual ou institucional.

Esta definição quando ancorada na concepção de Domingues (2002) e traduzida para os direitos de crianças e adolescentes, diz que a solidariedade materializada por meio da responsabilidade compartilhada por família e sociedade civil, no tocante à efetividade e garantia desses direitos necessita para além do corpo institucional do Estado, relações individuais e coletivas, seja familiar ou comunitária, pautadas no benefício coletivo.

Portanto, a solidariedade possui diversas dimensões concretizadas na vida social e implica no comprometido do agir individual e coletivo das instâncias privadas para a garantia dos direitos de crianças e adolescentes no marco da proteção integral.

\section{Considerações finais}

Pelas razões de ordem teórica expostas ao longo do trabalho, foi possível verificar que a constitucionalização do direito privado ocorrida no paradigma mais recente do constitucionalismo, não implica consubstancialmente na abrangência por parte da Constituição dos códigos e demais leis infraconstitucionais de natureza especial, mas no fato de que após a instauração de novos preceitos e valores constitucionais, todo o ordenamento infraconstitucional, incluindo aquelas leis e códigos que regulam as relações privadas, obrigatoriamente deverão se adequar a estes preceitos e valores.

Tanto o processo legislativo quanto os critérios hermenêuticos deverão, obrigatoriamente, considerar a Constituição, situação que torna possível afirmar que se passou de um direito civil codificado para um direito civil constitucionalizado, ou seja, não mais existe a autonomia que historicamente o direito civil sempre possuiu. Esta alteração mostrou-se necessária sob a perspectiva da aplicabilidade das normas civilistas nas relações privadas, tendo em vista a centralidade da Constituição Federal, suas normas e princípios. 
No tocante a abordagem teórica, importa considerar que a ideia de solidariedade que interessa a este trabalho parte do pressuposto de que os indivíduos e suas coletividades, ou seja, família e/ou comunidade estão inseridos em uma dimensão complexa, o que torna suas relações privadas integrantes do todo social, do qual o Estado não é excluído.

Desta forma, a sociedade torna-se lócus ideal de liberdade do indivíduo, de colaboração mútua e espaço harmonioso por meio do qual dialogicamente serão efetivados direitos e deveres numa lógica de solidariedade. Logo, a solidariedade e a liberdade individual devem ser coordenadas e harmonizadas para que, juntamente com os novos princípios constitucionais, se possa promover o diálogo entre ordenamento jurídico e espaço social, reordenando as relações privadas no sentido de efetividade dos valores constitucionais.

No entanto, esta abordagem implica na vinculação dos atores das relações privadas, ou seja, os particulares ao conteúdo mais significativo da Constituição Federal: os direitos fundamentais e, especificamente, aqueles que dizem respeito aos direitos de crianças e adolescentes.

Foi necessário relatar aspectos da eficácia desses direitos que verticalmente vincula o Estado em duas dimensões: primeiro na implementação e garantia de direitos, organizados por meio de sua estrutura institucional e de políticas públicas; e segundo no dever de atuação por meio de sua estrutura nos casos de violação e abusos de direitos fundamentais pelos particulares em suas relações privadas e sociais, seja de ofício por determinação legal ou por meio de provocação dos próprios indivíduos. No entanto, o respeito aos direitos fundamentais dos demais, o que caracteriza inicialmente a vinculação dos particulares aos direitos fundamentais, é um dever de todos, sem exceção.

Assim, resta sustentar que a ideia de sistema implica na vinculação e eficácia obrigatória das relações privadas aos direitos fundamentais, excluindose por óbvio, aquela seara que compete exclusivamente ao Poder Público. Essa vinculação, na perspectiva do constitucionalismo e seus valores, como a liberdade e principalmente a igualdade, é necessária ao reordenamento paradigmático que a Constituição Federal promoveu ao Direito da Criança e do Adolescente, no tocante à base principiológica e ao Sistema de Garantia de Direitos e seus atores, cuja responsabilidade pelos direitos fundamentais e 
garantias requer não apenas a atuação do Estado, mas o dever de agir de todos, nos casos de ameaça ou violação aos direitos.

Na seara de conduta dos indivíduos e suas relação privadas, portanto, a família, a comunidade local e a sociedade em geral, em que pese este dever de responsabilidade solidária se manifestar, em um primeiro momento por imposição legal, tendo em vista que é "dever da família, da sociedade e do Estado" garantir com prioridade absoluta os direitos fundamentais da população infanto-juvenil, de acordo com o artigo 227 da Constituição Federal, a solidariedade, neste caso, se apresenta como elemento imperativo de forma a coordenar a atuação dos indivíduos e sociedade que moralmente passam a se sentir responsáveis pela garantia dos direitos de crianças e adolescentes.

Essa internalização na consciência individual e social da responsabilidade pelos direitos de todas as crianças requer a solidariedade social, de forma que essa se torne um valor objetivamente moral e imperativo das regras que pautarão os indivíduos na sociedade, tanto seus direitos quanto seus deveres. Por essa razão, foi abordada a ideia de Duguit para explicitar a responsabilidade compartilhada na instância da família e da sociedade como a mais adequada.

Diante das situações de violação de direitos a que crianças e adolescentes estão expostos, se buscou demonstrar que o Direito da Criança e do Adolescente, ao elencar a tríplice responsabilidade compartilhada, trazendo para a instância do dever de garantia de diretos, a família e a sociedade em geral, o fez de forma a promover a solidariedade na seara além da estatal, fortalecendo o papel do direito como instrumento de transformação da realidade social manifesta nas relações privadas.

A transformação ocasionada pela solidariedade não pode e nem deve ficar unicamente a cargo do Estado, mas deve obrigatoriamente ser desempenhada pelos indivíduos no âmbito das relações privadas, tendo em vista que estes muitas vezes estão mais próximos das violações e da possibilidade de atuação para enfrentá-las.

\section{Referências}

BAGATINI, Julia. A responsabilidade civil na sociedade de risco e a ideia de solidariedade: uma abordagem a partir da Constitucionalização do 
direito privado. (Dissertação de Mestrado em Direito). Universidade de Santa Cruz do Sul - UNISC, 2014.

BRASIL. Constituição da República Federativa do Brasil. Promulgada em 05 de outubro de 1988. Disponível em: <http://www.planalto.gov.br/>. Acesso em: 20 de jun. 2020.

BRASIL. Lei No. 8.069, de 13 de julho de 1990. Dispõe sobre o Estatuto da Criança e do Adolescente e dá outras providências. Disponível em: $<$ http://www.planalto.gov.br/>. Acesso em 20 de jun. 2020.

CARDOSO, Alenilton da Silva. Princípio da solidariedade: o paradigma ético do direito contemporâneo. São Paulo: Juarez de Oliveira, 2010.

CARVALHO. Osvaldo Ferreira de. A Constitucionalização e a Internacionalização dos Direitos Fundamentais. Revista da Defensoria Pública da União. n. 43 Jan/fev.2012.

CONRADO, M.; PINHEIRO, R. F. (Coords.). Direito Privado e Constituição: ensaios para uma recomposição valorativa da pessoa e do patrimônio. Juruá: Curitiba, 2009.

CUSTÓDIO, André Viana. Os novos direitos da criança e do adolescente. Revista Espaço Jurídico, v. 7, jan/jun, Joaçaba: Unoesc, 2006.

CUSTÓDIO, André Viana. Teoria da proteção integral: pressuposto para compreensão do Direito da Criança e do Adolescente. Revista do DireitoUNISC v.29, 2008.

DOMINGUES, José Maurício. Interpretando a modernidade: imaginário e instituições. Rio de Janeiro: FGV, 2002.

DUGUIT, Léon. Fundamentos do direito. São Paulo: Martin Claret, 2009.

DURKHEIM, Émile. Da divisão do trabalho social. São Paulo: WMF Martins Fontes, 2010.

ETZIONI, Amitai. La tercera vía hacia uma buena sociedad: propuestas desde el comunitarismo. Madrid: Minima Trotta, 2001.

FACHIN, Luiz Edson. O Direito Civil contemporâneo, a norma constitucional e a defesa do pacto emancipador. In: CONRADO, M.; PINHEIRO, R. F. (Coords.). Direito Privado e Constituição: ensaios para uma recomposição valorativa da pessoa e do patrimônio. Juruá: Curitiba, 2009.

FACCHINI NETO, Eugênio. Reflexões histórico-evolutivas sobre a constitucionalização do direito privado. In: SARLET, Ingo Wolfgang. (Org.). Constituição, direitos fundamentais e direito privado. Porto Alegre: Livraria do Advogado, 2010.

FARIAS, José Fernando de Castro. A origem do direito de solidariedade. Rio de Janeiro: Renovar, 1998.

HABERMAS, Jürgen. A inclusão do outro: estudos de teoria política. São Paulo: Loyola, 2004.

LEAL, Mônia Clarissa Hennig. Jurisdição Constitucional aberta: reflexões sobre a legitimidade e os limites da jurisdição constitucional na ordem democrática. Uma abordagem a partir das 
teorias constitucionais alemã e norte-americana. Rio de Janeiro: Lumen Juris, 2007.

LEAL, Rogério Leal (Org.). Direitos sociais e políticas públicas: desafios contemporâneos. Santa Cruz do Sul: Edunisc, 2003.

MORIN, Edgar. A ética do sujeito responsável. In: CARVALHO, Edgard de Assis (Org.). Ética, solidariedade e complexidade. São Paulo: Palas Athena, 2000.

OLIVEIRA, Marcelo Andrade Cattoni de. Direito constitucional. Belo Horizonte: Mandamentos, 2002.

ONU. Organização das Nações Unidas. Convenção sobre os Direitos da Criança. 1989. Disponível em: <http://www.onu-brasil.org.br/>. Acesso em 15 jun. 2020.

PEREIRA, Tânia da Silva Pereira. Estatuto da Criança e do Adolescente: Estudos sociojuridicos. Rio de Janeiro. Renovar, 1996.

PERLINGIERI, Pietro. O direito civil na legalidade constitucional. Rio de Janeiro: Renovar, 2008.

PIOVESAN, Flávia. A Constituição Brasileira de 1988 e os Tratados Internacionais de Proteção dos Direitos Humanos. Disponível em: $<$ http://200.195.147.74/faculdade/revista_direito/3edicao/Artigo\%203.pdf $>$. Acesso em: 15/11/2019.

PIOVESAN, Flávia; IKAWA, Daniela (coords.) Direitos Humanos: fundamentos, proteção e implementação. Vol. 2. Curitiba: Juruá, 2007.

RAMIRES, Rosana Laura de Castro Farias. Reflexões sobre a proteção dos direitos humanos das crianças. In: PIOVESAN, Flávia; IKAWA, Daniela (coords.). Direitos Humanos: fundamentos, proteção e implementação. Vol. 2. Curitiba: Juruá, 2007.

RAPOSO, Clarissa Tenório Maranhão. Infância e violência doméstica: tendências e perspectivas na defesa dos direitos das crianças e adolescentes no município de Maceió. Disponível em: $<$ http://www.bdtd.ufpe.br/tedeSimplificado//tde_busca/arquivo.php?codArqu ivo $=412>$. Acesso em: 15 fev. 2020.

REIS, Jorge Renato dos. A construção do direito privado e o novo código civil. In: LEAL, Rogério Leal (Org.). Direitos sociais e políticas públicas: desafios contemporâneos. Santa Cruz do Sul: Edunisc, 2003.

SANTOS, Murilo Rezende dos. As funções da boa-fé objetiva na relação obrigacional. Revista de Direito Privado, São Paulo, n. 38, p. 205-26o, abr. 2009.

SARLET, Ingo Wolfgang. A eficácia dos direitos fundamentais. Porto Alegre: Livraria do Advogado, 2012.

SARLET, Ingo Wolfgang (Org). A Constituição concretizada: construindo pontes com o público e privado. Porto Alegre: Livraria do Advogado, 2000. SARMENTO, Daniel. Direitos Fundamentais e Relações Privadas. Rio de Janeiro: Lumen Juris, 2006. 
Revista Brasileira de História \& Ciências Sociais - RBHCS

Vol. $12 N^{\circ}$ 24, Julho - Dezembro de 2020

SILVA, Virgílio Afonso da. A constitucionalização do direito: os direitos fundamentais nas relações particulares. São Paulo: Malheiros, 2008.

VERONESE, Josiane Rose Petry. Estatuto da Criança e do Adolescente: Um novo paradigma. In: VERONESE, Josiane Rose Petry; LÉPORE, Paulo Eduardo; ROSSATO Luciano. Estatuto da Criança e do Adolescente: 25 anos de desafios e conquistas. São Paulo: Saraiva, 2015.

VERONESE, Josiane Rose Petry; VIEIRA, Cleverton Elias. Limites na educação: sob a perspectiva da Doutrina da Proteção Integral, do Estatuto da Criança e do Adolescente e da Lei de Diretrizes e Bases da Educação Nacional. Florianópolis: $\mathrm{OAB} / \mathrm{SC}$ Editora, 2006. 